\title{
CASE STUDIES IN LARGE AND SMALL CLASSES: COMMON APPROACHES, DIFFERENT RESPONSES
}

\author{
John Doran, Margaret Healy, Maeve McCutcheon and Steve O'Callaghan \\ University College Cork
}

\begin{abstract}
This paper explores the case study experience in large and small undergraduate classes, with a view to identifying and comparing the challenges which exist in each setting. Using open-ended student surveys and lecturer reflections, the study compares how students in large and small classes, drawn from similar backgrounds, experienced two case events. Contrary to expectations, positive responses were reported in the large class setting as well as in the small class setting. However, managerial factors dominated in the large classes, reducing opportunities for engagement. Different class dynamics were also observed in each setting. Significant differences in expectations were identified between students in large and small class settings regarding participation and interaction. Raising the expectations of students in large classes emerged as a challenge to educators.
\end{abstract}

\section{INTRODUCTION}

The changing role of the accountant in society makes demands for an array of personal and interpersonal skills in communication, negotiation and organisation, as well as the requisite technical and business knowledge of the profession. While case-based teaching approaches have been proposed as one way of advancing the development of such skills and knowledge in accounting education (Hassall, Lewis and Broadbent, 1998; Boyce, Williams, Kelly and Yee, 2001; Cullen, Richardson and O'Brien, 2004), little empirical evidence exists supporting their use in large class settings. 
Prior research has established a number of benefits arising from case-based teaching. Cases provide a valuable opportunity to bring relevance and reality into the classroom, promoting the integration and application of the underlying knowledge base (Boyce et al., 2001). Case-based teaching allows for the introduction of realism, via the use of real world scenarios (Weil, Oyelere, Yeoh and Firer, 2001; Rippin, Booth, Bowie and Jordan, 2002; Cullen et al., 2004); the use of judgement in resolving uncertainties, with no single right answer existing (Campbell and Lewis, 1991; Libby, 1991); the discussion and debate of alternative answers (Adler and Milne, 1997); and the practical demonstration of technical skills and knowledge, as part of the development of broader critical understanding of the accounting discipline (Booth, Bowie, Jordan and Rippin, 2000; Maltby, 2001).

Moss and McMillen (1980) consider the issue of how to develop problemsolving skills in large undergraduate classes, stating that for many undergraduate programmes there is a belief that time constraints and perceptions of student expectations can lead to an emphasis on subject-specific content, at the expense of the development of transferrable skills. In this context, improvements to teaching focus on the use of effective delivery mechanisms such as better audiovisual facilities (Craig, 2000), rather than emotional issues concerning students' ability to cope. Jackson and Prosser (1989) describe this approach to learning as follows:

In the lecture the emphasis is on the content or product. The product is the knowledge, transferred from the lecturer's notes to the student's notes. For most students this is the goal since it provides the key to the examination and other work to be done on a course. There is only a little process learning in the lecture. The student learns how to learn from lectures. This is a survival skill for a student. However, after graduation few will have the occasion to learn from lectures (Jackson and Prosser, 1989, p. 55).

Adler, Whiting and Wynn-Williams (2004), in the context of teaching cost and management accounting, point to the importance of the manner in which case studies are used, emphasising how the level and extent of student involvement determine their effectiveness. While the inherent 'plasticity' of the medium (Rippin et al., 2002) allows lecturers to capitalise on the established benefits of case-based teaching in business education, obtaining these benefits in accounting classes depends upon many factors, including the case materials, the setting and the roles of the lecturer and students (Campbell and Lewis, 1991). In the specific context of large class settings, it is argued that students are less likely to achieve higher-order learning outcomes and to become actively engaged in the teaching and learning activities.

The specific objective of this paper is to explore the case study experience in large and small undergraduate classes, with a view to identifying and comparing the challenges which exist in each setting. The paper is organised as follows: the next section reviews existing research on the use of case-based teaching and presents the need for additional evidence in the context of large class settings; the research context and the choice of data collection techniques are described in the following section; the research evidence is then presented, followed by discussion 
of the experiences of case-based teaching with large classes. Conclusions and recommendations for ongoing research are discussed in the final section.

\section{CASE-BASED TEACHING IN LARGE CLASS SETTINGS}

The use of case studies offers benefits both within and beyond the accounting curriculum. Within the accounting curriculum case-based teaching demands that students move from rote learning to beginning to analyse realistic scenarios and to integrate into the case context broader insights from across a module and programme of study (Libby, 1991). In addition, beyond the explicit curriculum, case-based teaching enables the integration of soft skills and facilitates personal development opportunities in team work and presentation skills (Stout, 1996). The case medium allows students to experience independent learning, peer learning and personal validation, if carefully managed. However, the use of case-based teaching in large class settings is not without difficulties. While there is little empirically based evidence investigating this specifically, some insight into the problems of large class settings generally does exist. For students, difficulties occur relating to participation, collective learning and peer interaction. Students are slow to participate in a context where large numbers of the class are unknown to them. With fragmented student groups, reluctant to prepare and participate, business lecturers in turn require significant class management skills (Booth et al., 2000).

The context of the original Harvard MBA case-based model includes classes of mature post-experiential learners who are usually acculturated with teambuilding and bonding exercises and opportunities. In contrast, participation in a large undergraduate class is more challenging and it becomes easier to seek to hide and hope the lecturer will not notice this amongst the greater number of students requiring attention (Booth et al., 2000). Collective learning - learning with others - is also difficult where individual students are less likely to know each other. If classes are mixed as well as large, students and instructors need to negotiate the logistical difficulties imposed in managing the requirements of different programmes and timetables. Peer interaction - learning from others - becomes harder in this environment, as students are less likely to question each other and difficulties in so doing become heightened by the lack of familiarity experienced in what for many is a very unfriendly situation (Islam, 2001). For example, the final report of the Australian Teaching Large Classes Project states:

Principles of good teaching and learning such as communication and negotiation, linking theory with practice and encouraging metacognition are often harder to build into the large class context. Large classes make it harder to personalise lectures, engage and maintain attention and create interaction (Australian Universities Teaching Committee, 2003, p. 13).

For lecturers, two interrelated aspects of the large class setting - the managerial and the educational (Biggs, 2003) - pose difficulty. Managerial concerns include the need to operate within strict time constraints and to adapt to the built environment. 
Doran, Healy, McCutcheon and O'Callaghan

Constraints on student time, lecturer time and class time become more acute (Hassall et al., 1998) and require careful balancing of teaching and learning activities both inside and outside of scheduled contact hours. A built environment which is conducive to a lecturing style of teaching for large numbers will not satisfy the prerequisites considered by many as necessary for case-based teaching (Knechel, 1992; Adler, Milne and Stringer, 2000; Erskine, Leenders and Mauffette-Leenders, 2003). Dealing with a large number of students, engaged in activities that are unfamiliar to them, creates a need for highly structured protocols to avoid chaos ensuing (Jackson and Prosser, 1989; Stout, 1996).

Educational concerns include the design of activities to facilitate the multiple perspectives on issues offered via case-based teaching, whilst avoiding the repetition that leads to student disengagement; the formulation of assessment strategies which take into account the level of resources available (Knechel, 1992; Adler et al., 2000); the need for rigor and fairness; and the balancing of form versus content and product versus process. Both lecturers and students can be reluctant to move from a traditional lecture or tutorial style of teaching, particularly in the context of large class sizes (Adler et al., 2000). Students become unwilling to participate, disinclined to speak out, assuming a more passive role on the assumption that their inactivity is less likely to be noticed in a larger class (Booth et al., 2000; Australian Universities Teaching Committee, 2003). However, the broader literature in education and the social sciences indicates that most undergraduate students are more willing to change than lecturers may give them credit for (Moss and McMillen, 1980; Islam, 2001) and can work without constant direct lecturer involvement in the teaching and learning activities (Jackson and Prosser, 1989). This also applies in the accounting area; for example, Brooks and Oliver (2004) in their postcard from the podium state:

Provided the subject content and modes of delivery are interesting and relevant, most students are generally willing to try something different. ... Well structured case-based work can be a useful vehicle to engage students in a productive learning environment outside of the formal classroom - in a virtual classroom - wherever the student is located (Brooks and Oliver, 2004, p. 116, emphasis as per original).

Stout (1996) reports that undergraduate accounting students found the case analysis aspect of the case study experience to be simultaneously interesting, valuable and difficult. Booth et al. (2000, p. 73) argue that their data suggest 'a set of strong tensions in the use of case studies' in large undergraduate business programmes. Pressures arising from what they term 'the massification in higher education' (Booth et al., 2000, p. 65) are affecting both teaching practice and pedagogic intent in the use of case studies in large undergraduate business programmes. Whilst research since then has acted to examine this, specific evidence in the context of large class settings is still required (Booth et al., 2000; Rippin et al., 2002).

This paper addresses the need for research specifically focused on the case experience in large undergraduate classes. The study explores case-based teaching in small and large class settings with the objective of identifying and comparing the managerial and educational problems that arise in each setting. The research approach adopted is described in the following section. 
Case Studies in Large and Small Classes: Common Approaches, Different Responses

\section{RESEARCH APPROACH}

Two case events designed for large class settings were also used in small class settings, involving student groups of similar background and level of prior studies. The majority of the students were in the penultimate year of a specialised degree in either Accounting or Finance. These students were taught together but subdivided into two cohorts for placement purposes; hence both case events occurred twice. The majority of students went on placement in the second semester; therefore in the first semester the cohort of students being taught was large while in the second semester it was small. The classes were defined as 'large' based on the relationship between the number of students, the teaching and learning activities and the facilities available. This is in accordance with the final report of the Teaching Large Classes Project of the Australian Universities Teaching Committee (2003). In the context of this study, the large classes numbered 84 students and the smaller classes up to 45 students.

The first case event (used with both large and small classes) formed part of a module examining the governance, regulation and control of financial organisations, which was assessed entirely by continuous assessment. The case study used examined internal control systems in WorldCom [Kaplan, R. and Kiron, D. (2004). Accounting Fraud at WorldCom, Harvard Business School, case study \#104107]. The case assignment accounted for 25 per cent of the total marks for the module. Two assessment points were chosen: an in-class presentation and a reflective written submission. A debate format was designed, which, it was felt, would facilitate a higher degree of student participation in the large class setting than the standard approach to case teaching. Students were assigned into groups, such that in the large class the size of each group was six students; in the small class, groups consisted of five students. In both the small and large classes, two programmes were represented and student groups were not mixed by programme. Debate motions dealing with aspects of the case were distributed to students. Prior to coming to class, each group was asked to prepare to debate on all the motions.

At the start of the debate class all groups were given a short period to prepare a single slide to argue their assigned side of a designated motion. In class, one member of each group debated one side of one of the seven motions, using only the single slide to accompany the presentation, and with a limit of five minutes allowed in which to present their arguments. Following each motion, the class as a whole was asked to vote on the motion, based on the arguments made. An individual post-class assignment served as the means of enabling the students to reflect on the materials covered, integrating the seven motions in the construction of a coherent understanding of the topic area generally.

The second case event (used with both large and small classes) was part of a business finance module and was the responsibility of a different lecturer to the first event. The case study used examined a potential acquisition by Cadbury Schweppes of Adams, a chewing gum company [Collis, D., Stuart, T. and Smith, T. (2008). Cadbury Schweppes: Capturing Confectionery (A), Harvard Business School, case study \#708453]. The format for the case study session was a 'Meeting of the Board of Directors of Cadbury Schweppes'. Students were allocated into groups 
with six students per group in the large class and five students in the small class. In these events, the student groups were mixed across programmes. Each group was assigned individual perspectives from which to analyse the proposed acquisition and was required to submit a short analysis of the acquisition to the lecturer the day before the case study session. Groups nominated one member to present their analysis to the single board meeting, which was chaired by the lecturer, acting solely as a facilitator. Following the board meeting, the same groups then reconvened to decide whether, as shareholders in Cadbury Schweppes, they would vote in favour of the acquisition. They were then asked to declare their position and justify it. After the case study session, groups were required to submit a short analysis of the acquisition from the perspective of a shareholder in the acquiring firm. The case assignment accounted for 30 per cent of the students' overall grade for the module.

Each event was designed to harness elements of 'structured conflict' (Pearce, 2002), leading to greater in-class student interaction and the recognition and appreciation of multiple viewpoints. In each instance the format adopted (a debate and a boardroom meeting) represented a novel classroom experience for all of the students concerned. The same case material was delivered in both the large and small class settings. A strict timeline was established for the conduct of the inclass activities. The lecturer provided students with detailed written instructions on the tasks which were to be completed before, during and after each individual case study event, as well as work to be completed in small groups prior to the case event class session itself. Students were allocated to groups by the module lecturer, with each group having a direct involvement in the combined classroom activities through their chosen representative.

Student feedback was gathered using an anonymous survey administered at the end of each case event session. Table 1 presents the response rates. The survey posed a series of open-ended questions to students regarding what they felt they had learned in the class; what aspects of the process worked well and what aspects didn't work well; and what changes could be made. The use of open-ended questions, whilst more time consuming to analyse given the total of 214 responses, allowed respondents to answer in their own terms, unconstrained by researcher perceptions of possible responses (Brennan, 1998; Bryman and Bell, 2003) and was deemed appropriate given the exploratory nature of the underlying research objective (Saunders, Lewis and Thornhill, 2009).

While the use of open-ended questions helped ensure the capture of an authentic student voice in the responses, the researchers were careful to avoid oversimplification in the drawing of comparisons between those responses. Bryman and Bell (2003) refer to the possibility of measurement error which may arise from the use of open-ended questions. Mindful of this, each of the four researchers independently analysed all of the survey responses collected over multiple readings of those responses and determined an initial categorisation of their content. At this point, the initial broad themes suggested by the literature - managerial and educational - were developed and expanded in light of the student responses. Interresearcher consistency in cataloguing of the student responses was greater than 90 per cent across all questions, suggesting a strong degree of reliability in the analysis. Responses generating divergent categorisations were reviewed and discussed 
in light of similarities with other responses, to establish concurrence across all four researchers.

TABLE I: SURVEY RESPONSE RATES

\begin{tabular}{llll}
\hline & Sample Size & Response Rate & \% Response Rate \\
\hline 'The Debate' & & & \\
Large group & 84 & 79 & $94 \%$ \\
Small group & 35 & 33 & $94 \%$ \\
'The Board Meeting' & & & \\
Large group & 84 & 67 & $80 \%$ \\
Small group & 45 & 35 & $78 \%$ \\
\hline
\end{tabular}

Jackson and Prosser (1989) stress the importance of looking at the large class context from both the student and the lecturer points of view. Lecturer inputs were collected via the compilation of a series of pre- and post-event reflections. One of the researchers (not involved with any of the case events) acted as a 'critical friend' (Kember, Ha, Lam, Lee, Ng, Yan and Yum, 1997), observing the learning environment and bringing increased rigor and objectivity to the research process. The critical friend, however, played no part in the teaching and learning process.

\section{RESEARCH FINDINGS}

The objective of this paper is to explore the case study experience in large and small undergraduate classes, with a view to identifying and comparing the challenges which exist in each setting. The data were collated and analysed from the perspectives of the students, the lecturers and the non-participant critical friend observer. Each of these is set out in the following sub-sections and illustrated with representative quotes.

\section{The Student Perspective}

Students were asked to comment on what they learned from the case experience, what worked well, what didn't work well and what could be improved. As the questions were open-ended, students could raise more than one issue in their responses. Appendix 1 summarises the responses to the student surveys, under each of four headings. Responses were categorised by large and small class students and a two proportion $z$-test was used to identify statistically significant differences between large class and small class responses. Where significant differences in response emerged, the underlying concerns were further explored. It should be noted from the outset that with all classes the tone of the survey responses was very positive. Both large and small classes welcomed the novel class formats, as illustrated in the following typical response:

Very interesting; better than an ordinary class; easier to further develop understanding of case. 
Doran, Healy, McCutcheon and O'Callaghan

There was little difference between large and small classes in the nature of their comments on the overall learning experience. Their most frequent response in each instance related to subject specific knowledge such as, for example, the complexities of mergers or the role of financial analysts in relation to WorldCom as part of the first case event. Students also, although less frequently, alluded to soft skills or competencies such as group work and presentation skills, as shown in the following example from one student listing what was learned by them following the debate format:

How to debate in front of an audience, keep composure, be articulate.

In a minority of instances students' insights suggested personal development, beyond the subject-specific content of the case event; for one student this was recorded as the recognition that:

People can see things in a very different way than you do.

When asked about what worked well, the general design of the case event used (i.e. that of a debate or a board meeting) was most frequently identified as a positive feature of the experience. In the large class 49 per cent of responses and in the small class 35 per cent of responses commented favourably on matters relating to the class format. However, two significant differences between the large and small class settings emerged in the responses to this question. The students in the large classes commented more frequently on management issues. In particular, students noted the lecturers' skill in managing a large number of individual contributions in a short space of time. For example, one student from a large class setting commented on the lecturer's role in managing the time available in the following terms:

Timing - was regulated firmly and no group had an unfair advantage.

This 'timing' aspect was raised by 24 per cent of students in the large class settings compared with 6 per cent of the students in the smaller classes, a difference which is significant at 1 per cent. In contrast, the students in the small class settings commented more frequently on the positive aspects of their in-class experience, with 45 per cent of students raising such issues compared to 14 per cent of students in the larger class settings, significant at the 1 per cent level. For example, one student from a small class setting listed what worked well as being:

Ultimately the responses to the arguments - back and forth discussion works best for learning in my opinion.

Students were also invited to consider aspects that didn't work well. The most common response from both groups (24 per cent from the large classes and 33 per cent from the small classes) concerned the detail of learning activities, for example:

[Use of] acetates - maybe should be PowerPoint instead; some of the presentations were not constructed well. 
The large classes differed from the smaller classes in their level of concern about an informal peer evaluation mechanism which was used in the debates. The structure was a series of motions with the groups on either side drawn from students of the two different programmes, Accounting and Finance. At the end of each motion being debated, the class as a whole was asked to vote on which argument won. The survey responses indicated that in the large class setting, students voted on programme lines, but yet as individuals were quick to condemn the group behaviour. For example, one student in the large class setting described the process in the following terms:

The voting system - totally biased; people vote for people in their course - FACT!

In the small class setting, although the same peer evaluation format was used, problems were raised in only 6 per cent of responses as compared to 33 per cent in the large class, a difference which is significant at 1 per cent. The small class, by contrast, emphasised aspects of the student experience which did not work well, and in particular they stressed the lack of opportunities for participation. For example, one student commented in relation to the first case event that there was:

... no debate side of presentations; sometimes you learn most from asking and answering questions and POIs [points of information] from your classmates.

These aspects were raised in 31 per cent of responses from the small class setting but only in 5 per cent of responses from the large classes, a difference which is significant at 1 per cent.

The smaller classes were also more critical of a design feature common to both the case events which required one representative to speak on behalf of the group as a whole, effectively delegating responsibility to one student for part of the grades of the group. In many of the student groups the preparatory work was divided between members, with each student completing discrete parts. In the case event sessions the group representatives may not have used all of the material prepared by the group members. This left some students feeling that their work was not recognised, either by their peers or by the lecturer, since it was never presented to the class. Issues of this nature appeared in 17 per cent of responses in the small class setting and only 4 per cent in the large class setting, a difference which is significant at 1 per cent.

The final element of the student survey concerned changes which the students had suggested. The changes suggested were generally consistent with the negative aspects students had identified earlier on. Thus, overall the suggestions most frequently made related to the detail of learning activities (in 35 per cent of the small class responses and 31 per cent of the large class responses). For example, one student suggested that that the lecturer for the debate should:

... get groups to do up slides for all motions - pro and con - and hand these up so that all group members had to review all the motions rather than focus on any individual motion. 
Doran, Healy, McCutcheon and O'Callaghan

Only 9 per cent of responses from the large class settings were directed at the student experience. By contrast, in 23 per cent of responses from the small class setting, changes were suggested to improve the student experience, with an emphasis on widening participation, a difference which is significant at 1 per cent. The large class suggested altering or scrapping the informal peer evaluation system used in the first case event. This was an issue for 16 per cent of the large class responses but only 2 per cent of the small class responses, a difference which is significant at 1 per cent. A higher proportion of the large class responses (16 per cent compared to 5 per cent in the small class responses (significant at 5 per cent)) advocated changes in group composition. Students who complained about mixed programme groups advanced reasons such as logistical difficulties in arranging meetings, lack of familiarity with other group members and difficulty in assigning tasks to the most appropriate group member.

\section{The Lecturer Perspective}

Both lecturers concluded that their respective case event sessions had been worthwhile. In all instances, there was a strong level of case analysis which exceeded expectations. The students displayed good verbal skills but other communication skills such as managing visual presentation aids were less impressive. Attendances were high and the students in class were polite and attentive. For example, the lecturer responsible for the second case event commented as follows:

The attitude of the students not participating in the [board] meeting was a concern before the session. I expected some students to disengage as the meeting was taking place; however from looking around the room most students were actively listening and noting pertinent points being made.

Managerial issues were more of a concern in the large class settings, overshadowing the experience from the lecturer perspective, especially with the debate format of the first case event. In reflecting on the large class experience, that lecturer recounted his experience in the following terms:

... pressure from conflict of administration versus academic issues, especially once the debate got going. The administrative issues distracted me from paying the full attention I would like to give to each presentation for grading purposes.

There was a marked difference noted in both of the small class setting case events, as compared to the large class settings, in the level of engagement of students. Even those students who would not be called on to present displayed a higher level of activity and engagement. For example, one of the lecturers noted that in the small class setting:

Nearly everybody in the room seems engaged in activity rather than just watching others work. 
Both lecturers independently commented that in the small class setting the students appeared to identify with the positions or roles they were asked to defend. When considering the difference between the large class iteration and the subsequent small class iteration of each of their respective case events, representative comments in this regard were as follows:

\begin{abstract}
Students discussing the case in one way actually behave quite similarly to the characters in the case that they are discussing. Those who are tasked in the debate to defend the actions of particular characters tend to concentrate of the failings of other characters who could have prevented the problems in the case.

The board meeting itself proceeded quite differently to the previous session. Students were much more animated and committed to their perspective. On a number of occasions there was heated 'back and forth' between students on particular points.
\end{abstract}

Both lecturers reported that the students in the small class settings appeared more comfortable. The potential impact of dominant personalities in the smaller group setting was also recognised. In the board room setting of the second case event, the dynamic which developed was attributed to one student who was particularly trenchant in his views. The lecturer summed this up as follows:

Had this student not been at the meeting I'm not sure if the same dynamic would have developed. This suggests that the personalities involved in the session are key determinants of how it will develop.

The lecturers also welcomed greater time for feedback in the smaller class setting which was provided by having fewer groups with fewer students.

\title{
The Critical Friend Perspective
}

The 'critical friend' commented favourably on the level of pre-class preparation undertaken by the students and their attention to the proceedings for all four of the case events. In general, the students had a good level of attendance, had analysed the cases in advance, and were motivated to learn during class. The most notable differences between the large and small class settings related to time constraints, atmosphere, participation and feedback.

Time constraints had a noticeable impact on the use of the debate format of the first case event in the large class setting, leading the critical friend to comment in the following terms:

The lecturer kept the process moving swiftly but this left little time for reflection. The lecturer did not comment on the individual points raised or on the presentation styles. There was no time for spontaneity, questions from the floor or rebuttals.

For both case event formats, the critical friend described the atmosphere as being less formal in the small class setting, as compared to the large class setting. While 
Doran, Healy, McCutcheon and O'Callaghan

group representatives participated, rather than the class a whole, the level of their participation was observed as being more forceful and the audience more engaged. The critical friend described this in one instance (for the small class setting) as follows:

Discussion took a while to get going but when it did, it really engaged the audience to the extent that they started to listen rather than taking notes.

A difference in the level of lecturer feedback given was also noted by the critical friend. Feedback was given and listened to in the small class settings. In the large class more time was taken up by presentations from student groups and no time was left for feedback.

\section{DISCUSSION}

Four key issues emerged from the analysis of the research data, as presented under each of the three perspectives described in the previous section. These were the impact of managerial issues, the level of student interaction, the desire to participate and the strength of programme identity. Each of these issues is discussed in the following paragraphs.

The impact of managerial issues was far more significant in the responses from the large classes, with more students highlighting timing and the format of the classes. Students recognised lecturers' efforts in ensuring equal time was given to all. This was not a significant concern for the small classes. Lecturers highlighted time pressure as a limiting factor in the conduct of case-based teaching in the large class settings, as a larger number of contributions had to be facilitated within the same limited time. In the small class settings, there was sufficient time for the lecturer concerned to give contemporaneous feedback on students' contributions and prompt discussion by questioning some of the points made. This engendered a more free-flowing, informal atmosphere.

The level of interaction observed, both between individual students and between students and the lecturer, differed markedly between the large and small classes. In the large class settings the students presented arguments, generally reading from notes, and these were not challenged by colleagues. There was little interaction between students beyond that required by the protocols of the case events. Students in the small classes had an objectively greater opportunity for interaction, due to the smaller class size, and in this setting points made were challenged by others and students were willing to defend their analyses against criticism. Students in the small classes noted and praised the free-flowing nature of the discussion during the sessions. Most of the negative comments on the experience related either to the standard of contributions made by other students or the absence of (even more) interaction between students.

Students in the small classes criticised the structure of the case sessions for not facilitating even greater participation and suggested amendments to the protocols to achieve this. The protocols designed for the case sessions provided for much of 
the analytical work to be completed in groups prior to class and for one member of each group to represent their group during the case session. In the small class settings, students clearly recognised the benefits of participation in the case discussion but many reported being dissatisfied with their own opportunities for participation in the sessions. They also felt cheated if work they had done at the preparatory stages was ultimately neither presented nor graded. In contrast, the students in the larger group were satisfied with the opportunity for participation available.

The participants in the case events underlying this research study largely comprised students from two undergraduate degree programmes. As evidenced in the research data, student reactions to working with peers either from within their own programme or across other programmes was quite different in the large and small class settings. Students in the small class settings did not focus on group composition to a significant extent and there appeared to be little concern about the assignment of either mixed or single-programme groups.

\section{CONCLUSIONS}

The purpose of this research was to explore the case study experience in large and small undergraduate classes, with a view to identifying and comparing the challenges which exist in each setting. Contrary to expectations, positive responses were reported in the large class setting as well as in the small class setting. The findings indicate that while managerial challenges were addressed, this did not resolve the reduced interaction and inhibited desire to participate that can arise in larger classes. The experience in the large class setting was constrained by timing and procedural concerns which reduced the potential for free-flowing spontaneous interaction between students and also inhibited the lecturers from providing informal immediate feedback. The challenge that remains is to reduce the impact of these managerial constraints on the educational experience of all participants.

One aspect of the approach adopted in the case event sessions was the use of novel formats, a debate and a board room setting, to create constructive conflict between students. The study found that the students in both classes were responsive to novelty but the students in large class settings did not fully engage with the case event sessions as learning opportunities. They both interacted less and demanded less opportunity for interaction than their peers in the small class settings. Their critique of the case event sessions revolved around structural and management factors and it appears that they were preoccupied with these issues to the extent that their expectations of the sessions as learning experiences were quite limited. The challenge for the future is to present the case event session as something more than a welcome distraction and emphasise its value as a learning opportunity, challenging and modifying student expectations of teaching and learning activities (identified by Boyce et al. (2001) as being the real problem with case-based teaching facing accounting educators).

A related but distinct issue to student expectations regarding interaction is the differing desire for participation evident in small and large class settings. Students in the small classes were eager to participate and dissatisfied when the format of 
the sessions limited their opportunities for individual participation. Students in the large classes did not express comparable concerns. Either they were satisfied with the low level of participation available to them or the possibility of greater participation simply did not occur to them. This was borne out by the lecturers' observations that students in the small classes participated and engaged more fully with the opportunities presented to them. The findings of this study complement the results of prior research regarding the relative passivity of the student role in larger classes (Adler et al., 2000; Booth et al., 2000; Australian Universities Teaching Committee, 2003). It is easier to hide and a lecturer is less likely to demand participation from a particular student. It is likely that there are weaker interpersonal links between students, making participation less attractive.

This study also points to an expectations gap whereby the students in the larger class setting, who are not normally afforded possibilities for participation, were satisfied by the limited opportunities available to them. In contrast, in the smaller class settings, students actively sought greater opportunities for participation. It may be that students do not miss what they don't have and want more of what they get. Addressing these differences in expectations is a first step towards working with the students to achieve higher levels of participation. Meeting their higher expectations is the second stage of this challenge.

The extent to which the class groups identified as cohesive units differed in the large and small class settings. In the small classes there was little evidence of students retaining a strong identification with their degree programme. In the large class settings students clearly categorised the class by programme and identified with their colleagues in the same programme. This created difficulties when the large classes were engaging in group work. There may be some critical small group size within which students can operate in comfort and that any large class setting is potentially simply a collection of smaller groups and will naturally sub-divide for comfort. It should be noted here that apart from the programme divisions, the large classes were homogenous with no identifiable differences in terms of age or ethnicity of the student members which could have provided alternative class groupings. In seeking to promote peer learning and peer interaction in a large class setting, this apparent tendency to cluster in smaller units and seek the comfort of the familiar needs to be considered. The challenge is to find ways of encouraging students to learn from and interact more with students from a variety of backgrounds and programmes.

In summary, the case study sessions proved a positive experience for students and lecturers alike in both the large and small class settings. However, in the large class setting managerial factors dominated student and lecturer responses. Student expectations were lower, notably in relation to participation and interaction. In addition, they were more hesitant in working with other students with whom they were unfamiliar. The challenges remaining for future research are to refine the managerial practices so that they don't constrain the educational experiences; to assist students in unlocking the potential benefits to them of fuller engagement with the case study sessions as an active learning experience rather than a passive but pleasant distraction; and to move beyond familiar groupings to develop skills in working and interacting across the broader student population. 
Case Studies in Large and Small Classes: Common Approaches, Different Responses

\section{ACKNOWLEDGEMENTS}

This paper is based on research carried out with financial support from the Irish Accountancy Educational Trust.

APPENDIX I: RESPONSESTO STUDENT SURVEYS

\begin{tabular}{|c|c|c|c|}
\hline Today I Learned & $\begin{array}{l}\text { Large Classes } \\
\quad(n=146)\end{array}$ & $\begin{array}{c}\text { Small Classes } \\
(n=68)\end{array}$ & z-stat \\
\hline Knowledge & $64 \%$ & $53 \%$ & 0.832 \\
\hline Competencies & $44 \%$ & $49 \%$ & 0.480 \\
\hline Personal insights & $18 \%$ & $18 \%$ & -0.0165 \\
\hline What Worked Well? & $\begin{array}{l}\text { Large Classes } \\
\qquad(n=|4|)\end{array}$ & $\begin{array}{c}\text { Small Classes } \\
(n=64)\end{array}$ & z-stat \\
\hline \multicolumn{4}{|l|}{ Managerial } \\
\hline Timing & $24 \%$ & $6 \%$ & $2.986 * * *$ \\
\hline Class format & $49 \%$ & $35 \%$ & $1.77^{*}$ \\
\hline \multicolumn{4}{|l|}{ Educational } \\
\hline Group work & $19 \%$ & $14 \%$ & 0.699 \\
\hline Student experience - pre-class & $1 \%$ & $6 \%$ & $1.769 *$ \\
\hline Student experience - in class & $14 \%$ & $45 \%$ & $4.784 * * *$ \\
\hline Learning activities & $26 \%$ & $20 \%$ & 0.782 \\
\hline Lecturer role & $8 \%$ & $9 \%$ & -0.019 \\
\hline What Didn't Work Well? & $\begin{array}{l}\text { Large Classes } \\
\quad(n=\mid 10)\end{array}$ & $\begin{array}{c}\text { Small Classes } \\
(n=48)\end{array}$ & z-stat \\
\hline \multicolumn{4}{|l|}{ Managerial } \\
\hline Environment & $9 \%$ & $2 \%$ & 1.631 \\
\hline Timing & $8 \%$ & $13 \%$ & 0.898 \\
\hline Group size & $5 \%$ & $2 \%$ & 0.69 \\
\hline \multicolumn{4}{|l|}{ Educational } \\
\hline Group work & $3 \%$ & $6 \%$ & 0.69 \\
\hline Student experience in class & $5 \%$ & $31 \%$ & $5.034 * * *$ \\
\hline Level of repetition & $12 \%$ & $4 \%$ & 1.585 \\
\hline Learning activities & $24 \%$ & $33 \%$ & 1.221 \\
\hline Assessment - burden on one & $4 \%$ & $17 \%$ & $2.926 * * *$ \\
\hline Assessment - task balance & $11 \%$ & $15 \%$ & 0.609 \\
\hline Peer evaluation & $33 \%$ & $6 \%$ & 4.11 $17 * *$ \\
\hline
\end{tabular}


Doran, Healy, McCutcheon and O'Callaghan

\begin{tabular}{lccc}
\hline \multicolumn{1}{c}{ What Could Be Improved? } & $\begin{array}{c}\text { Large Classes } \\
(\mathbf{n}=\mathbf{~ I ~} \mathbf{0})\end{array}$ & $\begin{array}{c}\text { Small Classes } \\
(\mathbf{n}=\mathbf{6 2})\end{array}$ & z-stat \\
\hline Managerial & $4 \%$ & $8 \%$ & 0.901 \\
Environment & $18 \%$ & $24 \%$ & 0.844 \\
Timing & $16 \%$ & $5 \%$ & $2.069 * *$ \\
Group structure & & & \\
Educational & $9 \%$ & $23 \%$ & $2.572 * * *$ \\
Student experience & $31 \%$ & $35 \%$ & 0.426 \\
Learning activities & $22 \%$ & $34 \%$ & $1.702 *$ \\
Assessment & $27 \%$ & $24 \%$ & 0.3 \\
Peer interaction & $16 \%$ & $2 \%$ & $2.789 * * *$ \\
Peer evaluation & $9 \%$ & $13 \%$ & 0.655 \\
Other < 6\% & & & \\
\hline
\end{tabular}

$* * *=$ significant at the $1 \%$ level; $* *=$ significant at the $5 \%$ level; $*=$ significant at the $10 \%$ level.

Note: As more than one response to each question by each student was allowed, the figures represent the percentages of students giving each response.

\section{REFERENCES}

Adler, R. and Milne, M. (1997). Improving the Quality of Accounting Students' Learning through Action-Oriented Learning Tasks, Accounting Education, Vol. 6, No. 3, pp. 191-215.

Adler, R., Milne, M. and Stringer, C. (2000). Identifying and Overcoming Obstacles to LearnerCentred Approaches in Tertiary Accounting Education: A Field Study and Survey of Accounting Educators' Perceptions, Accounting Education, Vol. 9, No. 2, pp. 113-134.

Adler, R., Whiting, R. and Wynn-Williams, K. (2004). Student-Led and Teacher-Led Case Presentations: Empirical Evidence about Learning Styles in an Accounting Course, Accounting Education, Vol. 13, No. 2, pp. 213-229.

Australian Universities Teaching Committee (AUTC) (2003). Teaching Large Classes Project 2001, Final Report, March 2003, Teaching and Educational Development Institute, University of Queensland, Australia, available from: <http:/ / www.tedi.uq.edu.au/largeclasses/ pdfs/AUTC_final_report.pdf>, accessed 05 November 2009.

Biggs, J. (2003). Teaching for Quality Learning at University: What the Student Does, Buckingham: Society for Research into Higher Education and Open University Press.

Booth, C., Bowie, S., Jordan, J. and Rippin, A. (2000). The Use of the Case Method in Large and Diverse Undergraduate Business Programmes: Problems and Issues, International Journal of Management Education, Vol. 1, No. 1, pp. 62-75.

Boyce, G., Williams, S., Kelly, A. and Yee, H. (2001). Fostering Deep and Elaborative Learning and Generic (Soft) Skill Development: The Strategic Use of Case Studies in Accounting Education, Accounting Education, Vol. 10, No. 1, pp. 37-60.

Brennan, N. (1998). Accounting Research: A Practical Guide, Dublin: Oak Tree Press.

Brooks, A. and Oliver, J. (2004). What Do You Mean: No Class Every Week? Postcard from the Podium, Accounting Education, Vol. 13, No. 1, pp. 115-117.

Bryman, A. and Bell, E. (2003). Business Research Methods, Oxford: Oxford University Press.

Campbell, J. and Lewis, W. (1991). Using Cases in Accounting Classes, Issues in Accounting Education, Vol. 6, No. 2, pp. 276-283. 
Craig, R. (2000). The Ringing 'Phone: 'Theatre' in a Large Group Lecture, Prototype 'Postcard from the Podium', Accounting Education, Vol. 9, No. 2, pp. 197-199.

Cullen, J., Richardson, S. and O'Brien, R. (2004). Exploring the Teaching Potential of Empirically-Based Case Studies, Accounting Education, Vol. 13, No. 2, pp. 251-266.

Erskine, J., Leenders, M. and Mauffette-Leenders, L. (2003). Teaching with Cases, third edition, Ontario: Ivey Publishing.

Hassall, T., Lewis, S. and Broadbent, M. (1998). Teaching and Learning Using Case Studies: A Teaching Note, Accounting Education, Vol. 7, No. 4, pp. 325-334.

Islam, R. (2001). Reflections on Large Class Teaching in the Social Sciences, Teaching Large Classes AUTC Project 2001, available from: <http://www.tedi.uq.edu.au/largeclasses/ case_studies/casestudy-06_islam.html>, accessed 05 November 2009.

Jackson, M. and Prosser, M. (1989). Less Lecturing, More Learning, Studies in Higher Education, Vol. 14, No. 1, pp. 54-68.

Kember, D., Ha, T., Lam, B., Lee, A., Ng, S., Yan, L. and Yum, C. (1997). The Diverse Role of the Critical Friend in Supporting Educational Action Research Projects, Educational Action Research, Vol. 5, No. 3, pp. 463-481.

Knechel, W. (1992). Using the Case Method in Accounting Instruction, Issues in Accounting Education, Vol. 7, No. 2, pp. 205-217.

Libby, P. (1991). Barriers to Using Cases in Accounting Education, Issues in Accounting Education, Vol. 6, No. 2, pp. 193-213.

Maltby, J. (2001). Second Thoughts about 'Cases in Auditing', Accounting Education, Vol. 10, No. 4, pp. 421-428.

Moss, G. and McMillen, D. (1980). A Strategy for Developing Problem-Solving Skills in Large Undergraduate Classes, Studies in Higher Education, Vol. 5, No. 2, pp. 161-171.

Pearce, R. (2002). Case-Based Structured Conflict: A Means for Enhancing Classroom Learning, Journal of Management Education, Vol. 26, No. 6, pp. 732-744.

Rippin, A., Booth, C., Bowie, S. and Jordan, T. (2002). A Complex Case: Using the Case Study Method to Explore Uncertainty and Ambiguity in Undergraduate Business Education, Teaching in Higher Education, Vol. 7, No. 4, pp. 429-441.

Saunders, M., Lewis, P. and Thornhill, A. (2009). Research Methods for Business Students, fifth edition, Harlow: FT Prentice Hall.

Stout, D. (1996). Experiential Evidence and Recommendations Regarding Case-Based Teaching in Undergraduate Cost Accounting, Journal of Accounting Education, Vol. 14, No. 3, pp. 293-317.

Weil, S., Oyelere, P., Yeoh, J. and Firer, C. (2001). A Study of Students' Perceptions of the Usefulness of Case Studies for the Development of Finance and Accounting-Related Skills and Knowledge, Accounting Education, Vol. 10, No. 2, pp. 123-146. 